\title{
Transplant Nursing
}

National Cancer Institute

\section{Source}

National Cancer Institute. Transplant Nursing. NCI Thesaurus. Code C20896.

Nursing care provided to the transplant recipient and donor. 